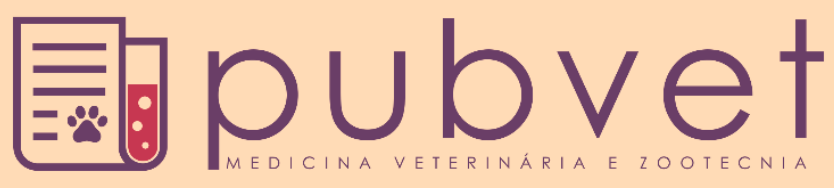

https://doi.org/10.31533/pubvet.v13n11a451.1-13

\title{
Levantamento de dados e causas de eutanásia em cães e gatos: avaliação ética-moral
}

\author{
Mariana Virgínia de Souza ${ }^{1 *}$, Izabela Andrade Pandolfi ${ }^{2}{ }^{\bullet}$, Romeu Moreira dos Santos ${ }^{3}{ }^{\circ}$, \\ Daniel Paulino Junior ${ }^{4} \bullet$
}

${ }^{1}$ Médica Veterinária. Tangará da Serra-MT Brasil.

${ }^{2}$ Médica Veterinária, especialista em Vigilância Sanitária. Uberaba-MG Brasil.

${ }^{3}$ Professor Doutor da Faculdade Dr Francisco Maeda. Ituverava-SP Brasil.

${ }^{4}$ Professor Doutor da Faculdade Dr. Francisco Maeda. Ituverava-SP Brasil.

*Autor para correspondência, E-mail: mariana.v.souza@hotmail.com

Resumo. Eutanásia é a morte humanitária de um animal, executada por um método que produz inconsciência rápida e subsequente morte, sem evidência de dor e/ou agonia, ou um método que utilize drogas anestésicas em doses suficientes para produzir a perda indolor da consciência seguida de parada cardiorrespiratória. O presente trabalho faz uma revisão bibliográfica abordando aspectos sobre a eutanásia em pequenos animais e traz um levantamento de casos em um período de 25 meses, em que foram atendidos 2.982 animais e desses, 41 foram eutanasiados sendo que $95,12 \%$ foram cães e 4,84\% eram gatos. As três principais causas de eutanásia neste levantamento foram respectivamente cinomose, fraturas de coluna e neoplasias.

Palavras chave: ética, eutanásia, medicina veterinária

\section{Data collection and causes of euthanasia in dogs and cats: ethical- moral evaluation}

\begin{abstract}
Euthanasia is the humanitarian death of an animal, performed by a method that produces rapid unconsciousness and subsequent death, without the goal of reducing pain and / or agony, or a method that uses anesthetic drugs in doses sufficient to produce a loss of consciousness. The present work is a bibliographical review approach to euthanasia in small animals and to bring a survey process over a period of 25 months, in which 2,982 animals were attended and, 41 were euthanized, $95.12 \%$ of which were dogs and 4,84\% are cats. As three main causes of this euthanasia have now always been distemper, spine fractures and neoplasms.
\end{abstract}

Keywords: ethics, euthhanasia, veterinary medicine

\section{Recopilación de datos y causas de eutanasia en perros y gatos: evaluación ético-moral}

Resumen. La eutanasia es la muerte humanitaria de un animal, realizada por un método que produce inconsciencia rápida y muerte posterior, sin evidencia de dolor y/o agonía, $o$ un método que use medicamentos anestésicos en dosis suficientes para producir una pérdida de conciencia sin dolor, seguido de una interrupción cardiorrespiratoria. El presente trabajo se trata de una revisión bibliográfica que aborda aspectos sobre la eutanasia en pequeños animales y presenta un levantamiento de la casuística en un período de 25 meses, a los que asistieron 2.982 animales y de estos, 41 fueron sacrificados siendo que $95,12 \%$ 
eran perros y $4,84 \%$ eran gatos. Las tres causas principales de eutanasia em esta encuesta fueron moquillo, fracturas de columna y neoplasias respectivamente.

Palabras clave: ética, eutanasia, medicina veterinaria

\section{Introdução}

Eutanásia é a indução da cessação da vida utilizando métodos tecnicamente aceitáveis e cientificamente comprovados, observando sempre os princípios éticos (Aragão, 2012). Dentre as justificativas para realização da eutanásia estão: idade avançada, neoplasias, doenças músculo esqueléticas e neurológicas, problemas comportamentais, afecções do trato urinário e agente físico (Trapp et al., 2010). Os critérios a serem seguidos para a eutanásia têm por fundamento a utilização de métodos indolores que conduzam rapidamente à inconsciência e morte, que necessitem de contenção mínima, evite a excitação dos animais e que sejam apropriados para a idade, espécie e estado de saúde do paciente (Figueiredo \& Araújo, 2001). A eutanásia está dividida em métodos físicos ou químicos, sendo que os químicos podem ser decorrentes do uso de substâncias inalantes ou substâncias injetáveis, os quais são indicados como procedimento mais seguro e humanitário existente (Figueiredo \& Araújo, 2001) Os métodos físicos devem causar a perda imediata de consciência, mediante trauma físico cerebral (Figueiredo \& Araújo, 2001). Partindo do princípio de que os animais são seres sencientes é preciso estabelecer diretrizes e normas que garantam o atendimento aos princípios de bem-estar animal e o respeito aos parâmetros éticos durante a eutanásia (Aragão, 2012). As normativas e regras a serem seguidas durante a eutanásia são descritas pelo Conselho Federal de Medicina Veterinária na resolução $\mathrm{N}^{\mathrm{o}} 1000$ do ano de 2012.

O presente estudo avaliou os aspectos morais, éticos e legais envolvidos com a eutanásia veterinária. Para conhecer a realidade deste procedimento, foi feito um levantamento de todos os casos de eutanásia em pequenos animais, ocorridos em um Hospital Veterinário localizado na cidade de Ituverava, São Paulo, Brasil, no período de agosto de 2017 a março de 2019.

\section{Eutanásia: Etimologia e definição}

A palavra eutanásia derivada do grego eu (bom) e Thanatos (morte) que significa, vulgarmente, a boa morte, a morte calma, a morte doce, indolor e tranquila (Paganelli, 1997). Segundo Rivera et al. (2006), a eutanásia é o ato de cessar a vida por meio de métodos que induzam à rápida inconsciência e morte dos mesmos sem sofrimento. A eutanásia é uma prática antiga, na qual Francis Bacon, no ano de 1623 a utilizou pela primeira vez em seu trabalho denominado História vitae et mortis. Nesta obra, ele sustentava que os médicos deveriam ter a competência de abrandar pelas suas mãos os sofrimentos e agonia da morte (Campos \& Medeiros, 2011).

\section{Diferenças entre eutanásia, distanásia, ortotanásia e mistanásia}

A eutanásia é o procedimento capaz de cessar a vida de um animal, quando o mesmo apresentar condições incompatíveis com bem-estar físico ou psicológico, quando for utilizado em pesquisas ou quando representar perigo para a sociedade/meio ambiente (CFMV, 2002). Já a distanásia é o prolongamento exagerado da vida de um paciente onde, a atitude do médico responsável apesar de ter como objetivo salvar a vida do paciente, o submete a grande sofrimento, prolongando a vida a qualquer custo (Santana et al., 2010). A ortotanásia é o procedimento em que não existe mais fonte de cura para o paciente, deixando com que a morte chegue quando o organismo não possa mais sustentar a vida, sem a interferência de aparelhos ou métodos que possam adiar a morte (Villas-Bôas, 2008). Já o conceito de mistanásia refere-se à morte miserável dos excluídos, como é o caso dos animais de rua que não têm acesso a condições básicas de sobrevivência como alimentação e cuidados com a saúde, resultando em morte com sofrimento e prematuridade (Lopes, 2011).

\section{Indicações para eutanásia}

Menezes et al. (2005) apontam que as causas para realização da eutanásia em animais são diversas, incluindo problemas comportamentais, senilidade, enfermidades terminais, traumas, problemas neurológicos e urológicos. Podendo também o procedimento citado ser feito em 
pesquisas clínicas ou para garantia a saúde pública e preservação da faun a e meio ambiente (CFMV, 2013). Trapp et al. (2010) citam em seus estudos a existência também de casos de eutanásia sem que houvesse qualquer tipo de necessidade clínica aparente. A eutanásia deve ser realizada apenas se o bem-estar estiver comprometido de forma irreversível, se o animal for uma ameaça à saúde pública ou fauna nativa, se for utilizado em experimentos científicos ou quando o tratamento necessário representar custo incompatível com a atividade produtiva do animal (CFMV, 2012). Salientar todos esses critérios, impedindo que animais passem por eutanásia sem necessidade, é um dever ético e moral do médico veterinário (Agostinho \& Palazzo, 2009).

\section{Eutanásia humanitária em animais}

A eutanásia-humanitária se refere a uma forma indolor de garantir o bem-estar do animal quando o mesmo tiver que passar pelo procedimento de eutanásia como forma de aliviar seu sofrimento ou em situações que se encaixem nas descritas pelo Conselho Federal de Medicina Veterinária (CFMV, 2013).

O estresse durante todo o processo deve ser minimizado, devendo as técnicas ter sempre como resultado a rápida perda de função cerebral seguida de parada cardíaca, ressaltando o fato da importância do Médico Veterinário ser o responsável pelo processo (Ibrahim, 2012). É de suma importância que durante todo o processo o profissional responsável, tenha em mente a responsabilidade implicada, sendo indispensável possuir os prontuários, garantir os produtos que utilizará, acompanhar o processo e ter uma autorização assinada dos tutores do animal (CFMV, 2012). Outro aspecto importante é que o profissional conheça o animal, para que sejam avaliadas durante todo o tempo, as respostas fisiológicas frente à utilização dos diversos métodos de eutanásia (Magalhães, 2012).

\section{Normas e critérios para realização da eutanásia}

Considerando que a eutanásia é um procedimento clínico, sua responsabilidade fica inteiramente a cargo do médico veterinário, portanto, o mesmo deve seguir o código de ética da profissão durante todo o atendimento/procedimento bem como as resoluções sobre o tema (CFMV, 2012). O profissional deve ter em mente que apesar de inerente a profissão, a morte pode acarretar efeitos danosos tanto para os proprietários quanto para o médico veterinário, por isso a eutanásia deve ser indicada com critério (Pulz et al., 2011). Os critérios a serem seguidos na eutanásia têm por parâmetro, o uso de métodos indolores, que sejam rápidos, eficazes e irreversíveis, que seja seguro para o operador, que exijam o mínimo de contenção e que não cause estresse adicional, lembrando que deve ser indicado conforme a idade, espécie e saúde do animal (Aragão, 2012). Porém, antes de observar os critérios citados anteriormente, é preciso enfatizar o papel ético do médico veterinário neste processo, sendo ele o responsável por recomendar ou não o procedimento e acompanhar o mesmo (Agostinho \& Palazzo, 2009).

Segundo Booth \& McDonaldo (1992) um aspecto fundamental para a realização da eutanásia é o local onde é executado o procedimento, sendo ressaltado por Magalhães (2012) a necessidade da estrutura onde será realizada a eutanásia, ser distante de quaisquer outras salas ou alojamentos de outros animais. A instalação deve possuir estrutura correta para a aplicação de medicamentos pela via parenteral, como mesas de atendimento, armários para insumos, torneira com água potável e pia. Já o ambiente, deve ser agradável com o propósito de evitar situações estressantes tanto para os funcionários como para os animais, como pode ser observado na Figura 1 (Lumb, 1974). O piso deve ser lavável, antiderrapante e impermeável, enquanto as paredes devem ser de cores claras, lisas, laváveis e impermeáveis até o forro, sendo este de laje pintada (Reichmann, 2000).

Após a eutanásia os cadáveres devem ser embalados em sacos plásticos brancos leitosos (Figura 2) e transportados para o seu destino final em veículos adequados (World Society For the Protection Animal, 1999).

Todos os documentos relacionados ao paciente, inclusive o termo de autorização de eutanásia (Figura 3) devem ser arquivados, pois, em caso de não cumprimento das regras, o Médico Veterinário poderá responder a processo ético profissional (CFMV, 2012). 


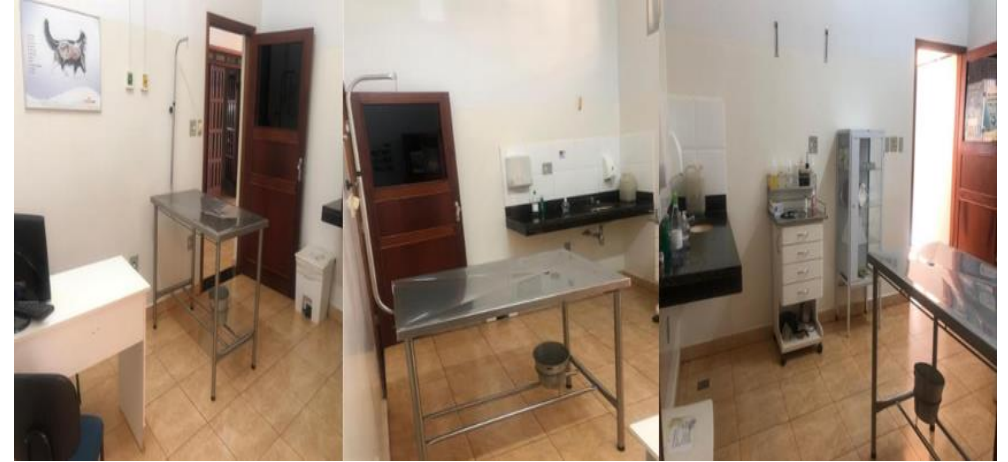

Figura 1. Figura representativa de um ambulatório ideal e que segue as normas de segurança/sanitária para a realização do procedimento de eutanásia em animais.

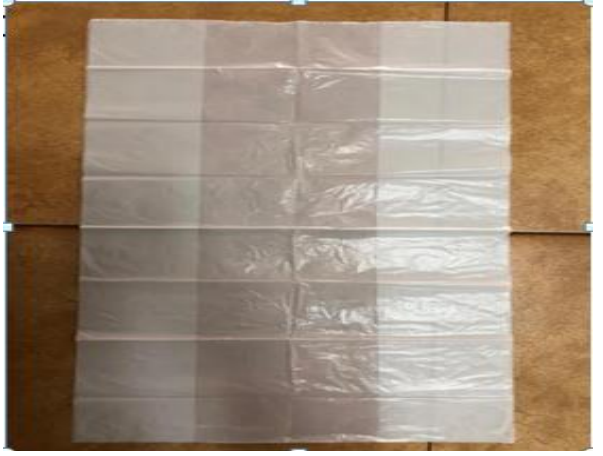

Figura 2. Saco branco que é utilizado para o acondicionamento dos cadáveres de animais.

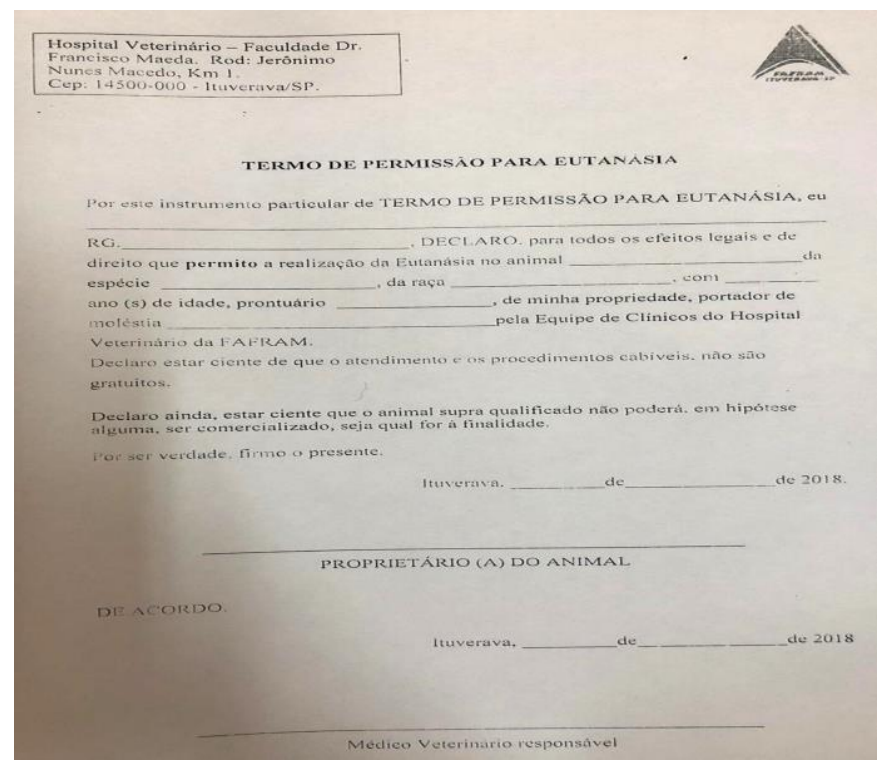

Figura 3. Imagem representativa do termo de eutanásia que deve ser assinado pelos tutores do animal antes que o procedimento seja iniciado. Este documento é indispensável e deverá ser armazenado junto ao prontuário do animal para quaisquer questionamentos.

\section{Métodos e técnicas para eutanásia}

A eutanásia pode ser realizada por métodos químicos ou físicos, dependendo de alguns aspectos observados caso a caso (Magalhães, 2012). A avaliação dos melhores métodos para efetuar a eutanásia em cada espécie animal pode ser feita de acordo com cinco parâmetros: rapidez, nível de experiência do operador, eficácia, segurança para o operador e valorização estética (aceitabilidade para o operador/espectador) (Fontes, 1995).

O método químico é baseado no uso de substâncias que produzam a inconsciência em seguida morte do animal, sendo utilizados primeiramente os anestésicos que podem ser gerais, inalatórios ou sedativos e, em seguida, o método pode ser complementado por injeção de bloqueador neuromuscular, cloreto de potássio ou injeção de lidocaína na cisterna magna (BRASIL, 2018). A utilização de outros medicamentos como o T61 seguido ou não de anestesia geral e o sulfato de galamina seguido do cloreto de potássio também são utilizados (Agostinho \& Palazzo, 2009). Cabe ao médico veterinário definir o protocolo que será utilizado na rotina do hospital veterinário ou clínica (Figura 4), podendo ser modificados de acordo com a necessidade do paciente (Agostinho \& Palazzo, 2009).

Natalini (2007) cita que os barbitúricos são os fármacos de eleição para realizar a eutanásia visto que são potentes e capazes de promover a inconsciência do paciente em poucos instantes e, quando utilizados via intravenosa em dose e concentração ideal, leva o animal a uma morte indolor. Porém, essa classe de 
medicamentos também tem pontos negativos como a possibilidade de o animal apresentar respiração agônica, o que é visualmente desagradável (BRASIL, 2018). Em trabalho realizado por Agostinho \& Palazzo (2009) foram listados diferentes protocolos para realização da eutanásia em cães e gatos, sendo que os dois de maior utilização segundo o estudo, podem ser observados na Tabela 1. Papich (2012) cita a utilização do protocolo 1:1 com Tiopental e Propofol a 2,5\% ou seja, a mesma quantidade de um medicamento é utilizada do outro medicamento.

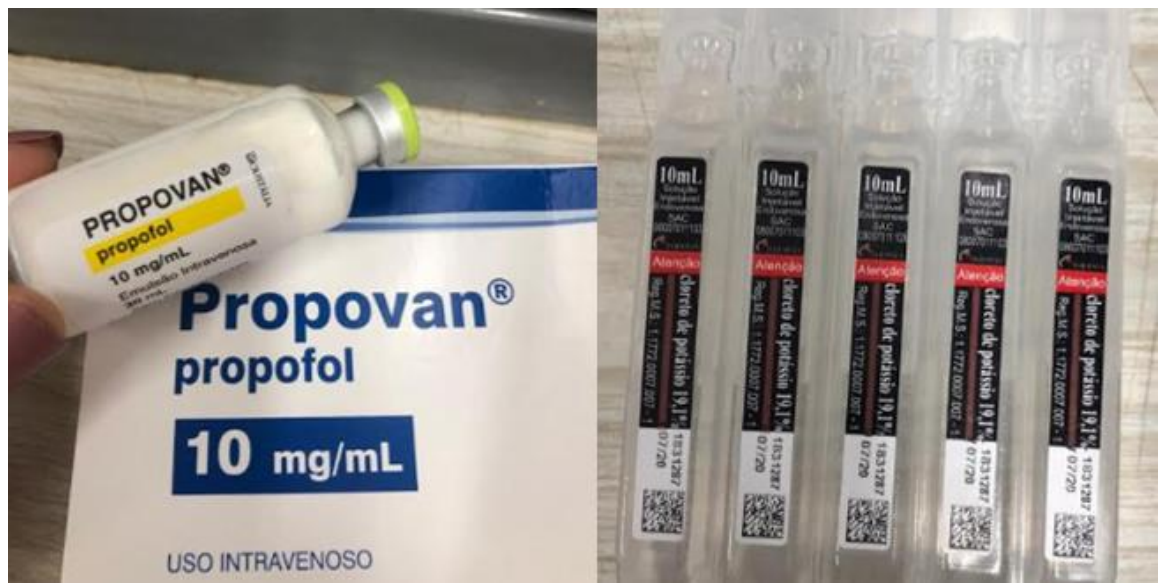

Figura 4. Protocolo químico utilizado no Hospital Veterinário, local do estudo. A esquerda está a imagem do Propofol, um anestésico geral utilizado primeiro e, na imagem da direita está o Cloreto de Potássio, utilizado após o Propofol, causando a assistolia.

Oliveira et al. (2003) citam que tais medicamentos que podem compor o método químico de eutanásia, apesar de exigirem experiência do operador, tem como pontos positivos ser rápido, eficaz e não promover deformidades no animal.

Tabela 1. Protocolos químicos mais utilizados para eutanásia em cães e gatos, segundo estudo realizado em 2009

\begin{tabular}{llr} 
Propofol ou & $6,6 \mathrm{mg} / \mathrm{kg}$ (cães) e $7 \mathrm{mg} / \mathrm{kg}$ (gatos) & Administração \\
Tiopental+ & $10-25 \mathrm{mg} / \mathrm{kg}$ (cães) e $5-10 \mathrm{mg} / \mathrm{kg}$ (gatos) & Intravenosa \\
Cloreto de Potássio & $1 \mathrm{ml} / \mathrm{kg}$ (cães e gatos) & Administração \\
\hline Acepromazina+ & $0,1 \mathrm{a} 0,2 \mathrm{mg} / \mathrm{kg}$ (cães e gatos) & Intravenosa \\
Tiopental+ & $10-25 \mathrm{mg} / \mathrm{kg}$ (cães) e $5-10 \mathrm{mg} / \mathrm{kg}$ (gatos) & \\
Cloreto de Potássio & $1 \mathrm{ml} / \mathrm{kg}$ (cães e gatos)
\end{tabular}

Fonte. Adaptado de Agostinho \& Palazzo (2009), Papich (2012) e Jopeu (2013).

Já os métodos físicos devem causar a perda imediata de consciência, mediante trauma físico cerebral (concussão, deslocamento cervical, decapitação, eletrocussão e armas de fogo) e podem ser necessários quando a utilização de drogas compromete os resultados desejados na pesquisa (Oliveira et al., 2003). Para mamíferos os métodos físicos são aceitos com restrição, podendo ser utilizados a eletrocussão posterior à anestesia geral ou tiro com arma de fogo em atuações a campo, sendo este exclusivo para animais selvagens (BRASIL, 2018). Apesar de ser aceito como um método físico para algumas espécies, a decapitação demonstrou ser um método que gera estresse durante o procedimento, visto que ocorre a concentração de catecolaminas neste período (Agostinho \& Palazzo, 2009; Paganelli, 1997). Tal procedimento não deve ser utilizado para cães e gatos e, para animais que passam pelo procedimento para atender as necessidades humanas, não deve ser empregado o termo eutanásia (Oliveira et al., 2003). Independentemente do método utilizado para eutanásia, seja ela feita em qualquer espécie, é imprescindível que a morte do animal seja confirmada por um profissional capacitado, que observe a parada cardíaca associada à avaliação de outros parâmetros fisiológicos (BRASIL, 2018). Ressalta-se que apesar de existirem medicamentos frequentemente utilizados para eutanásia, o veterinário deve ter em mente que cada organismo reage de uma forma a determinada droga e, por vezes, podem existir reações adversas (Oliveira et al., 2003). 


\section{A eutanásia como método ultrapassado de profilaxia contra zoonoses}

As principais zoonoses que são controladas a partir do método de eutanásia são a raiva e a leishmaniose(Ibrahim, 2012). A raiva é uma doença aguda do Sistema Nervoso Central (SNC) que pode acometer mamífero e seres humanos, caracterizada por encefalomielite fatal causada por vírus do gênero Lyssavirus, destaca-se o fato de que os animais de estimação são as principais fontes de transmissão para humanos (Morato et al., 2011). O homem se contamina pelo vírus da raiva por meio do contato com a saliva do animal doente, não existindo a necessidade de uma mordida, basta que uma ferida ou corte entre em contato com a saliva do animal contaminado (Kotait et al., 2007). Após a contaminação o vírus se dirige para o Sistema Nervoso Central, variando o tempo de inoculação com a natureza do vírus, o local da inoculação e a quantidade inoculada (Ibrahim, 2012).

Já a leishmaniose é uma doença crônica, de manifestação cutânea ou visceral, causada por protozoários flagelados do gênero Leishmania (Monteiro et al., 2005). É uma zoonose comum no cão e no homem, sendo que no homem é transmitida pela picada de mosquitos flebotomíneos, que compreendem o gênero Lutzomyia (conhecidos como "mosquito palha" ou "birigui") e Phlebotomus (Gontijo \& Melo, 2004). Existem dois tipos mais comuns de leishmaniose que são: leishmaniose visceral ou calazar e a leishmaniose tegumentar ou cutânea (Ibrahim, 2012). A leishmaniose visceral é uma doença sistêmica crônica grave, potencialmente fatal para o homem e para o animal, que acomete vários órgãos internos, principalmente o fígado, o baço e a medula óssea (Gontijo \& Melo, 2004). Já a leishmaniose tegumentar é uma doença não contagiosa, de evolução crônica, que acomete as estruturas da pele e cartilaginosas da nasofaringe, de forma localizada ou difusa (Basano \& Camargo, 2004).

Para certificar o controle da saúde pública existem órgãos espalhados pelo Brasil chamados Centro de Controle de Zoonoses (CCZ) que têm como função controlar as zoonoses, acolher animais e principalmente disseminar conhecimento para população (Fraga \& Monteiro, 2014). Os institutos para controle de zoonoses realizam trabalhos educativos, capturam animais errantes (serviço conhecido normalmente como "carrocinha") e, estão autorizados a praticar a eutanásia em animais, desde que realizada com métodos humanitários em prol da chamada higienização urbana, caso não haja outra opção (Ibrahim, 2012).

Santana (2006) contestam, entretanto, a política de controle de zoonoses adotada por órgãos como o CCZ que além da captura, faz o confinamento e extermínio dos animais, visto que para este não existe um protocolo seguido, por vezes, indo contra os princípios de eutanásia humanitária. Santos \& Montanha (2011) trazem em seus estudos a existência de correntes favoráveis e contrárias a prática da eutanásia na medicina veterinária, sendo esta uma das áreas mais delicadas na veterinária e que exige do profissional, amplo conhecimento sobre o tema para criar sua própria opinião.

\section{Eutanásia como alternativa de pôr fim ao sofrimento do animal}

Os animais domésticos estão assumindo um papel importante na sociedade, tornando-se membros das famílias e, por consequência, o cuidado com o bem-estar desses animais é crescente (Quinton, 2005). Sabendo da importância desses seres e de sua senciência, a preocupação com o fim da vida e as práticas existentes para aliviar sofrimento, caso ele exista, são constantes (Junges et al., 2010).

Sendo a eutanásia uma alternativa a barrar o sofrimento do paciente, não é aceitável que o animal apresente comportamento que indique estresse desnecessário durante o procedimento, tais como a vocalização, agressividade, salivação, midríase, tremores, espasmos musculares, entre outros (Oliveira et al., 2003).

\section{Os animais como detentores do direito à vida}

Com o passar dos anos, a necessidade de oferecer boa qualidade de vida aos animais, envolvendo não só a plena condição física, mas também a psicológica, ganha forças e, isso é devido ao fato de que a visão da sociedade a respeito desses seres vem mudando drasticamente (Teixeira et al., 2018). Uma nova conformação social, onde ocorre à inclusão dos animais no contexto familiar ressalta ainda mais a necessidade de promoção, proteção e valorização da vida desses seres (Pulz et al., 2011). Tendo em vista essa nova visão sobre os animais, leis foram criadas e aperfeiçoadas, tendo como objetivo reconhecer os animais como detentores do direito à vida $\mathrm{e}$, tal fato gera mudanças na medicina veterinária, que é o elo entre 
humanos e animais (Faraco \& Seminotti, 2004). As leis criaram responsabilidades para os proprietários, que passaram a ter a guarda do animal e não mais a posse, sendo cabíveis a eles as decisões que garantam o bem-estar, atenda às necessidades do animal e estejam em conformidade com a legislação (Osório, 2013).

\section{Material e métodos}

Foram analisadas 2.982 fichas clínicas de felinos e caninos atendidos no período compreendido entre março de 2017 a maio de 2019 no Hospital Veterinário localizado em Ituverava, São Paulo. Dessas, foram selecionadas as fichas cuja resolução do caso findou em um procedimento de eutanásia, tanto em cães quanto em gatos. A seleção incluiu todos os casos de eutanásia independente da raça, idade, sexo, diagnóstico final e método de eutanásia que os animais em questão foram submetidos.

Todas as fichas foram separadas e selecionadas manualmente no Hospital Veterinário e em seguida os dados foram compilados em Excel. Os resultados foram obtidos após análise estatística descritiva utilizando método de porcentagem. Os gráficos presentes neste estudo foram elaborados utilizando os resultados gerais e de porcentagem no programa Excel.

\section{Resultados e discussão}

Os resultados obtidos após levantamento de casos de eutanásia em cães e gatos em um período de 25 meses mostrou que das 2.982 fichas de atendimento, 41 resultaram em eutanásia, o que representa pouco mais de $1 \%$ dos casos. A porcentagem de eutanásias realizadas foi superior ao índice encontrado por Menezes et al. (2005) com 0,95\% de eutanásias em cães e gatos em seus estudos. Dos 41 casos, 39 eutanásias foram realizadas em cães $(95,12 \%)$ e dois em gatos $(4,87 \%)$ (Gráfico 1).

\section{Porcentagem de animais eutanasiados por espécie}

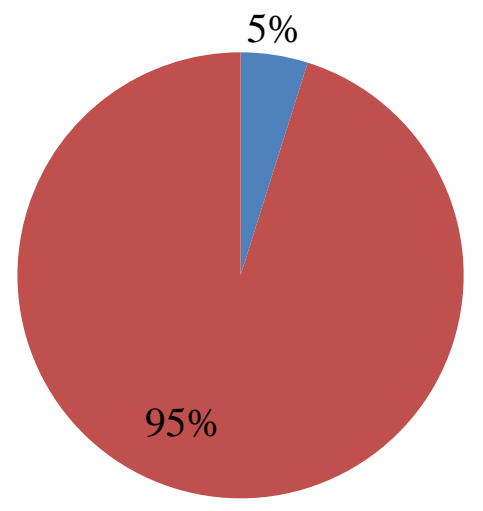

- Felinos

- Caninos

Gráfico 1. Gráfico comparativo entre cães e gatos obtidos no Hospital Veterinário.

Com relação ao sexo de cães eutanasiados, 23 eram machos $(58,97 \%)$ e 16 eram fêmeas $(41,02 \%)$ e, no caso dos felinos, os dois animais eutanasiados eram machos (100\%). Os números foram próximos aos encontrados por Menezes et al. (2005), em que 54,2\% dos cães eram machos e 45,8\% eram fêmeas.

Diferentes motivos levaram a eutanásia dos animais observados neste estudo, sendo estes agrupados em 21 causas distintas. As três maiores motivações de eutanásia foram as seguintes: cinomose com 10 casos $(24,4 \%)$, fraturas de coluna com seis casos $(14,6 \%)$ e neoplasias em geral com cinco casos $(12,2 \%)$ (Gráfico 2).

A quantidade de animais com cinomose que o tutor não quis realizar a eutanásia foram mínimas.

A mudança do papel do animal no contexto familiar trouxe a ideia de que doenças infectocontagiosas teriam a incidência reduzida já que a preocupação com a garantia de bem-estar e longevidade dos animais é maior; porém, esta não é a realidade observada tanto na literatura quanto neste trabalho (Trapp et al., 2010). 


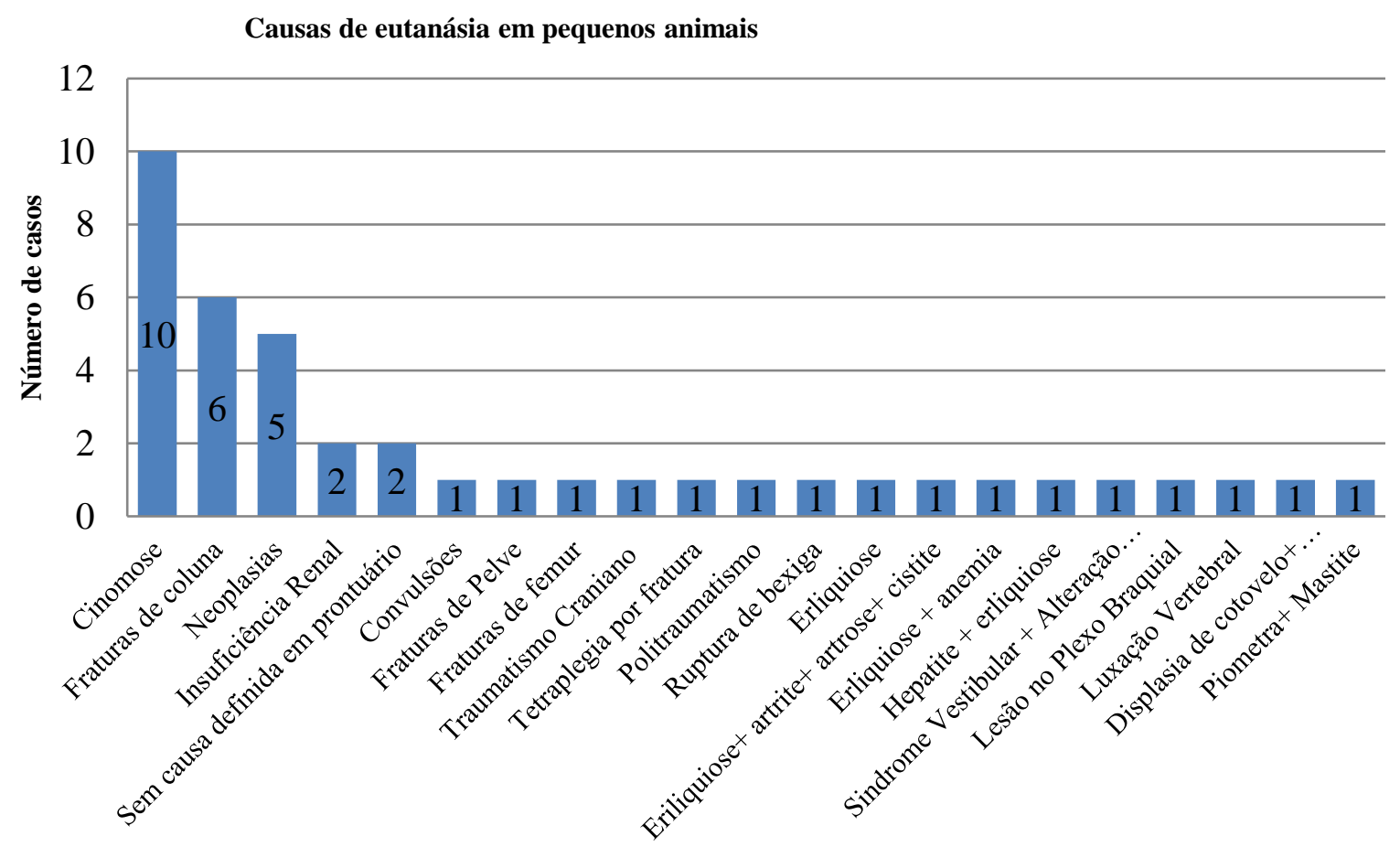

Gráfico 2. Representação gráfica do número de eutanásias realizadas em decorrência de cada diagnóstico.

A cinomose é um exemplo de doença contagiosa que pode ser evitada com a vacinação anual, porém, a mesma apresenta número de casos crescentes, que evoluem por vezes para a eutanásia como pôde ser observado neste levantamento de casos, sendo ela a maior causa (Silva et al., 2009). A rápida evolução do quadro, a degeneração nervosa progressiva e o alto custo para o tratamento são fatores que influenciam de forma significativa para o alto número de animais eutanasiados em razão da cinomose (Tilley et al., 2008; Tilley \& Smith, 2015).

Lesões traumáticas, principalmente fraturas vertebrais, ficaram em segundo lugar como causas de eutanásia, corroborando com os dados de Menezes et al. (2005), que encontraram índices de $7 \%$ de eutanásias realizadas após traumas, englobando as fraturas de coluna, fraturas de pelve, fraturas de fêmur, traumatismo craniano, tetraplegia por fratura e politraumatismo. Tal fato pode ser explicado pela severidade de alguns traumas, principalmente de coluna, em que existe a chance de comprometimento dos movimentos e qualidade de vida do animal (Mendes \& Arias, 2012). É necessário ressaltar também que o pós-operatório de animais submetidos a cirurgias ortopédicas demanda tempo e paciência do proprietário e, em casos de sequelas, existe ainda o fator de possível comprometimento da qualidade de vida do animal (Nelson \& Couto, 2015). Outro aspecto importante no que diz respeito à eutanásia motivada por traumas é que nem sempre o trauma em si é um motivo relevante para que o proprietário opte por eutanasiar o animal, sendo nesses casos chamada de eutanásia por conveniência (Fighera et al., 2008). Essa situação pode ser confirmada quando analisado o fato de que um dos animais fora eutanasiado por ter sofrido lesão de fêmur e outro por lesão de pelve, sem comprometimento de quaisquer outros órgãos.

Em trabalho realizado por Togni et al. (2018), os traumas físicos em felinos foram os maiores responsáveis pela realização da eutanásia e, no presente estudo, um dos felinos que foram eutanasiados, teve como diagnóstico poli traumatismo após atropelamento e o outro felino, não possuía em sua ficha qual o motivo da eutanásia.

As neoplasias foram a terceira causa de eutanásia neste estudo, mesmo que as mesmas não tenham sido especificadas e, segundo Andrade et al. (2012) as eutanásias em decorrência de tumores ocorrem devido ao prognóstico reservado ou desfavorável ou às complicações sistêmicas que podem surgir caso a neoplasia não seja tratada ou seja diagnosticada tardiamente. Neste levantamento, dos cinco casos de neoplasias, três foram em fêmeas o que é explicado por Pereira et al. (2010) que afirmam que tal situação 
ocorre pela maioria das neoplasias serem mamárias ou iniciarem nas mamas das fêmeas e por isso, o número de casos de eutanásia nas fêmeas em decorrência de neoplasias é maior.

A insuficiência renal foi uma das causas de eutanásia em cães neste levantamento, sendo identificados dois casos, porém, os mesmos não foram especificados. "A insuficiência renal aguda é caracterizada pelo acúmulo de toxinas urêmicas no organismo, desequilíbrio hidroeletrolítico e acidobásico e, quando não tratada pode evoluir para a insuficiência crônica e irreversibilidade do quadro" (Tilley et al., 2008; Tilley \& Smith, 2015). Quando crônica, dificilmente pode ser melhorada com medicamentos e, por esse motivo, o tratamento é apenas paliativo, visando diminuir a sintomatologia, podendo ser este o motivo de alguns proprietários optarem pela eutanásia dos pacientes (Nelson \& Couto, 2015). No presente estudo é possível notar que duas das 41 fichas em que os animais haviam sido eutanasiados, não havia o motivo do procedimento, o que impede que correlações sejam feitas com o objetivo de mostrar as principais enfermidades que resultam na eutanásia.

As alterações do sistema nervoso como síndrome vestibular e convulsões foram as causas de dois animais serem encaminhados ao processo de eutanásia. É relativamente comum que cães e gatos com quaisquer alterações neurológicas sejam eutanasiados, visto que existe mau prognóstico ou dificuldade para o manejo desses animais durante toda a vida (Santoro \& Arias, 2018). Assim como a convulsão a síndrome vestibular pode ser o resultado de diferentes patologias, portanto, antes de realizar a eutanásia, todas as possibilidades de reversão do quadro, devem ser avaliadas (Nelson \& Couto, 2015).

As rupturas de bexiga em cães são causadas com maior frequência em situações de traumas, como atropelamentos, por exemplo; porém, não podem ser descartadas causas menos comuns como a perfuração por urólitos, corpos estranhos ou durante procedimento cirúrgico. O uroperitôneo é uma consequência desta ruptura, que gera sintomas em longo prazo como desidratação, uremia, hipercalemia, hipovolemia e morte. Quando causada por trauma a ruptura de bexiga tem prognóstico excelente, porém, os eventos desencadeados pela ruptura podem levar a um diagnóstico reservado ou desfavorável (Bardela et al., 2007; Fossum, 2014; Pereira et al., 2013). Sendo assim, um caso em questão, que não possui maiores informações sobre a causa da ruptura, pode ter evoluído para uma eutanásia devido ao prognóstico desfavorável.

Quatro casos distintos de erliquiose seguida de eutanásia foram percebidos neste levantamento, sendo eles erliquiose; erliquiose somada à anemia; erliquiose com artrite, artrose e cistite e hepatite com erliquiose. A erliquiose é uma doença que pode assumir caráter agudo ou crônico, sendo que o primeiro quadro tem prognóstico positivo e o tratamento é apenas medicamentoso. Porém, quando crônica, a erliquiose é uma situação grave, onde o prognóstico pode ser ruim caso haja comprometimento medular (Nelson \& Couto, 2015; Tilley et al., 2008; Tilley \& Smith, 2015). Cabe ressaltar que a erliquiose pode exigir a internação do paciente para que além do protocolo medicamentoso usual, seja feita a estabilização do animal, quando este apresentar anemia severa ou distúrbios hepáticos e renais (Moraillon et al., 2013). Em um dos casos listados anteriormente, a erliquiose mesmo que com pouca frequência, pode gerar sério comprometimento hepático, elevando os níveis das enzimas fosfatase alcalina, alanina aminotransferase e aspartato aminotransferase, comprometendo assim a vida do animal (Sousa et al., 2010).

A lesão no plexo braquial que motivou a eutanásia em um cão atendido no Hospital Veterinário, baseia-se que este plexo é uma estrutura composta por um conjunto de nervos que inerva o membro torácico, sendo eles sensoriais e motores e, lesões nessa região não são incomuns. Quando possui origem traumática a afecção é denominada avulsão do plexo braquial e tem como resultado a paralisia grave no membro torácico (Arias \& Stopiglia, 1997; Freitas, 2010).

Para Freitas (2010) a utilização de tala para que o membro não seja forçado é fundamental e, deve ser aliada a fisioterapia, visto que na maioria dos casos ela evita a amputação do membro e permite a recuperação total ou parcial do movimento. Como pôde ser observado, para esta situação não existe indicação clínica para eutanásia, portanto, sugere-se que a mesma tenha sido realizada a pedido do proprietário por conveniência. Neste estudo foi observado um caso de eutanásia ocorrida após diagnóstico de luxação vertebral e, para este caso, faz-se a ressalva que a luxação não é uma fratura, mas também é motivada por um trauma e suas consequências, podendo incluir a perda de movimentos ou dor profunda (Mendes \& Arias, 2012). As sintomatologias listadas anteriormente são decorrentes de 
compressões no espaço interdigital ou em casos severos a Lesão medular e por este motivo, a avaliação clínica é fundamental para definir o prognóstico do paciente (Santos et al., 2012). Quando não existir lesão nervosa, com comprometimento irreversível da medula espinhal, o tratamento é possível, sendo direcionada a descompressão medular, estabilização da coluna e/ou prevenção da destruição neuronal (Araújo et al., 2012). Portanto, tendo em vista tais aspectos e o fato de que na ficha clínica não existiam maiores informações sobre o caso, não é possível inferir se houve a necessidade clínica ou por conveniência da eutanásia neste paciente. Ademais, é preciso observar que em um dos casos de eutanásia o animal apresentava dentre a displasia de cotovelo e trauma, o osteossarcoma que segundo Oliveira \& Silveira (2008) é um tumor ósseo, comumente observado em cães de meia idade e idosos, que gera sintomatologia de claudicação aguda ou crônica e inchaço no membro. O tratamento do osteossarcoma consiste na retirada do tumor sem amputação do membro (quando possível) ou amputação total do membro e quimioterapia. Quando em estágio avançado, com metástases e somado ao quadro clínico ruim do animal, o prognóstico é desfavorável e por este motivo alguns proprietários optam por realizar a eutanásia, abreviando o sofrimento do paciente (Daleck et al., 2002; Oliveira \& Silveira, 2008).

No período analisado houve um caso de eutanásia feita em decorrência de um quadro de piometra somado a mastite, porém, a conduta terapêutica deste problema é cirúrgica e não se aplicaria a eutanásia (Fossum, 2014). Entretanto, Kalenski et al. (2012) citam que alguns casos podem evoluir para a sepse, mudando o prognóstico do animal, visto que pode desencadear a falência múltipla de órgãos e levar o animal a morte em pouco tempo. Sabendo que na ficha clínica deste animal não constavam indícios de sepse, pode-se intuir que o pedido para realização da eutanásia partiu do proprietário. Deve-se salientar, ainda, que neste estudo em alguns casos a eutanásia não tinha indicação clínica, e tal situação não é incomum, sendo comprovada também no estudo de Fighera et al. (2008) que encontrou um índice de 7,4\% de eutanásias sem menções clínicas probatórias da necessidade de sua utilização.

\section{Conclusão}

A partir do levantamento de dados realizado, bem como o estudo feito acerca das questões envolvidas sobre a eutanásia em pequenos animais, pode-se afirmar que grande parte dos casos poderia ser prevenida com a utilização de medidas profiláticas, como por exemplo, a vacinação que muitas vezes não é feita por questões econômicas, falta de informação ou negligencia dos tutores. Porém, é necessário enfatizar que a decisão da eutanásia pode ter sido tomada por questões exclusivamente relacionadas aos tutores.

Tendo em vista todos esses aspectos é necessário enfatizar a necessidade e a importância da conscientização de tutores por meio de veterinários ou quaisquer outros profissionais capacitados a prestar esse serviço, ressaltando sempre que a qualidade de vida do animal depende em grande parte das ações que os humanos responsáveis por ele tomam durante toda a sua vida.

\section{Referências bibliográficas}

Agostinho, J. J. \& Palazzo, E. L. (2009). Aplicações clínicas e éticas da eutanásia em pequenos animais. Nucleus Animalium, 1(1):1-13.

Andrade, R. L. F. S., Oliveira, D. M., Dantas, A. F. M., Souza, A. P., Nóbrega Neto, P. I. \& Riet-Correa, F. (2012). Tumores de cães e gatos diagnosticados no semiárido da Paraíba. Pesquisa Veterinária Brasileira, 32(10):1037-1040.

Aragão, J. (2012). Guia Brasileiro de Boas Práticas em Eutanásia em Animais - Conceitos e Procedimentos Recomendados. Brasília, Brasil: CRMV.

Araújo, B. M., Fernandes, T. H. T., Souza, A. F. A., Diogo, C. C., Santos, C. R. O., Amorim, M. M. A. \& Tudury, E. A. (2012). Determinação do prognóstico em 37 cães com fraturas e luxações vertebrais toracolombares por meio da presença da postura de Schiff-Sherrington, reflexo extensor cruzado e o sinal de Babinski. Paper presented at the Anais XIII Jornada de Ensino, Pesquisa e Extensão (Jepex).

Arias, M. V. B. \& Stopiglia, A. J. (1997). Avulsão do plexo braquial em cães-1: aspectos clínicos e neurológicos. Ciencia Rural, 27(1):75-80. 
Bardela, G. T., Costa, I. L. O., Santos, C. E. M. d. \& Cremonini, D. N. (2007). Ruptura de bexiga ocasionada por urolitíase: Relato de Caso. Revista Científica Eletrônica de Medicina Veterinária, $\operatorname{IV}(8): 1-6$.

Basano, S. A. \& Camargo, L. M. A. (2004). Leishmaniose tegumentar americana: histórico, epidemiologia e perspectivas de controle. Revista Brasileira de Epidemiologia, 7328-337.

Booth, N. H. \& McDonaldo, L. E. (1992). Farmacologia e terapêutica em veterinária. Rio de Janeiro, Brasil: Guanabara Koogan.

BRASIL. Resolução Normativa CONCEA no 37/2018 que dispõe sobre a Diretriz da Prática de Eutanásia do Conselho Nacional de Controle de Experimentação Animal. Brasília, 15 de fevereiro de 2018.2 Disponível em: <https://www.mctic.gov.br/mctic/export/sites/institucional/institucional/concea/arquivos/legislacao /resolucoes_normativas/Anexo-Resolucao-Normativa-n-37-Diretriz-da-Pratica-de-Eutanasia_siteconcea-.pdf>. Aceso em: 02 mai. 2019.

Campos, P. B. \& Medeiros, G. L. (2011). A eutanásia e o princípio constitucional da dignidade da pessoa humana. Revista Eletrônica Direito, Justiça e Cidadania, 2(1):1-42.

CFMV - Conselho Federal De Medicina Veterinária. (2012). Resolução N 1000, de 11 de maio de 2012. Dispõe sobre procedimentos e métodos de eutanásia em animais e dá outras providências. Resolução 1000, p.1-9, 2012. Disponível em: <http://portal.cfmv.gov.br/lei/index/id/326.>Acesso em: 30 mar. 2019.

CFMV, Conselho Federal de Medicina Veterinária. Guia Brasileiro de Boas Práticas Para A Eutanásia em Animais. Conceitos e procedimentos recomendados. Brasília: CFMV, p. 15-66, 2013

Conselho Federal De Medicina Veterinária (CFMV). (2019). Resolução N 1000, de 11 de maio de 2012. Dispõe sobre procedimentos e métodos de eutanásia em animais e dá outras providências. Disponível em: <http://portal.cfmv.gov.br/lei/index/id/326.>Acesso em: 30 mar.

Conselho Federal DE Medicina Veterinária (CFMV). Guia Brasileiro de Boas Práticas Para A Eutanásia em Animais. Conceitos e procedimentos recomendados. Brasília: CFMV, p. 15-66, 2013.

Conselho Federal DE Medicina Veterinária (CFMV). Resolução N 1000, de 11 de maio de 2012. Dispõe sobre procedimentos e métodos de eutanásia em animais e dá outras providências. Resolução 1000, p.1-9, 2012. Disponível em: <http://portal.cfmv.gov.br/lei/index/id/326.>Acesso em: 30 mar. 2019.

Conselho Federal de Medicina Veterinária. (2019). Resolução 714, de 20 de junho de 2002. Dispõe sobre procedimentos e métodos de eutanásia em animais e dasoutrasprovidências.Disponível em: <https://www.ufrgs.br/bioetica/resolucao_1000-2012\%20CFMV.pdf >. Acesso em: 30 mar.

Daleck, C. R., Fonseca, C. S. \& Canola, J. C. (2002). Osteossarcoma canino-revisão. Revista de Educação Continuada em Medicina Veterinária e Zootecnia, 5(3):233-242.

Faraco, C. B. \& Seminotti, N. (2004). A relação homem-animal e a prática veterinária. Revista CFMV, 10(32):57-62.

Fighera, R. A., Silva, M. C., Souza, T. M., Brum, J. S., Kommers, G. D., Graça, D. L. \& Barros, C. S. L. (2008). Aspectos patológicos de 155 casos fatais de cães atropelados por veículos automotivos. Ciência Rural, 38(5):1375-1380.

Figueiredo, A. C. C. \& Araújo, F. A. A. (2001). Eutanásia animal em centros de controle de zoonoses. Revista do Conselho Federal de Medicina Veterinária, 2312-17.

Fontes, E. M. (1995). Métodos de Eutanásia. Revista Portuguesa de Ciências Veterinárias, 40104-109.

Fossum, T. W. (2014). Cirurgia de pequenos animais (4 ed. Vol. 1). São Paulo: Elsevier Brasil.

Fraga, L. d. S. \& Monteiro, S. (2014). A gente é um passador de informação: práticas educativas de agentes de combate a endemias no serviço de controle de zoonoses em Belo Horizonte, MG. Saúde e Sociedade, 23993-1006.

Freitas, A. I. A. (2010). Regeneração espontânea da lesão do plexo braquial no gato: Relato de caso. PUBVET, 4(147):1-5.

Gontijo, C. M. F. \& Melo, M. N. (2004). Leishmaniose visceral no Brasil: quadro atual, desfios e perspectivas. Revista Brasileira de Epidemiologia, 7(3):338-349. 
Ibrahim, T. (2012). Nutrição Experimental: Editora Rubio.

Jopeu. (2013). Drogas e doses para cães e gatos. Joinville, Santa Catarina: Clube dos Autores.

Junges, J. R., Cremonese, C., Oliveira, E. A., Souza, L. L. \& Backes, V. (2010). Reflexões legais e éticas sobre o final da vida: uma discussão sobre a ortotanásia. Revista Bioética, 18(2):275-288.

Kalenski, T. A., Reinoldes, A., Kitsis, M., Faustino, M., Talib, M. S. F. \& Cortopassi, S. R. G. (2012). Identificação das bactérias envolvidas na sepse grave de fêmeas caninas com piometra submetidas a ovário-histerectomia terapêutica. Brazilian Journal of Veterinary Research and Animal Science, 49(2):130-138.

Kotait, I., Carrieri, M. L., Carnieli Júnior, P., Castilho, J. G., Oliveira, R. d. N., Macedo, C. I., . . . Achkar, S. M. (2007). Reservatórios silvestres do vírus da raiva: um desafio para a saúde pública. Boletim Epidemiológico Paulista, 4(40):2-8.

Lopes, C. R. A. (2011). Eutanásia: a última viagem. Revista da Faculdade de Direito da UERJ, 1(19):1-26.

Lumb, W. V. (1974). Euthanasia by noninhalant pharmacologic agents [Veterinary medicine]. Journal American Veterinary Medical Association, 165(9):851-852.

Magalhães, L. E. (2012). A ciência e os animais de laboratório. Revista da Sociedade Brasileira de Ciência em Animais de Laboratório, 1(1):7-13.

Mendes, D. S. \& Arias, M. V. B. (2012). Traumatismo da medula espinhal em cães e gatos: estudo prospectivo de 57 casos. Pesquisa Veterinária Brasileira, 32(12):1304-1312.

Menezes, D. C. R., Quessada, A. M., Guimarães, A. L. S. \& Almeida, E. C. S. (2005). Eutanásia em pequenos animais em Teresina-PI. Semina: Ciências Agrárias, 26(4):575-579.

Monteiro, E., Silva, J. C. F., Costa, R. T., Costa, D. C., Barata, R. A., Paula, E. V., . . Dias, E. S. (2005). Leishmaniose visceral: estudo de flebotomíneos e infecção canina em Montes Claros, Minas Gerais. Revista da Sociedade Brasileira de Medicina Tropical, 38(2):147-152.

Moraillon, R., Legeay, Y., Boussarie, D. \& Sénécat, O. (2013). Manual Elsevier de Veterinária: Diagnóstico e tratamento de Cães, gatos e animais exóticos (7th ed.). Rio de Janeiro: Elsevier.

Morato, F., Ikuta, C. Y. \& Ito, F. H. (2011). Raiva: uma doença antiga, mas ainda atual. Revista de Educação Continuada em Medicina Veterinária E Zootecnia do CRMV-SP, 9(3):20-29.

Natalini, C. C. (2007). Teoria e técnicas em anestesiologia veterinária. Porto Alegre, Rio Grande do Sul, Brasil: Srtmed.

Nelson, R. W. \& Couto, C. G. (2015). Medicina interna de pequenos animais. Amsterdan: Elsevier Editora.

Oliveira, F. \& Silveira, P. R. (2008). Osteossarcoma em cães (revisão de literatura). Revista Científica Eletrônica de Medicina Veterinária, 4(11):1-7.

Oliveira, H. P., Alves, G. E. S. \& Rezende, C. M. d. F. (2003). Eutanásia em medicina veterinária. Escola de Veterinária, 11-14.

Osório, A. (2013). A cidade e os animais: da modernização à posse responsável. Revista Teoria \& Sociedade, 21(1):143-177.

Paganelli, W. (1997). A eutanásia. Jus Navigandi, 21-5.

Papich, M. G. (2012). Manual Saunders de Terapia Veterinária: Elsevier Health Sciences Brazil.

Pereira, L. I., Balarin, G. S. \& Tanaka, M. (2010). Estudo retrospectivo sobre causa de morte e eutanásia nos pacientes oncológicos no Hospital Veterinário da Universidade Norte do Paraná. Paper presented at the Anais do I Encontro Anual de Iniciação Científica, Guarapuava, Paraná, Brasil.

Pereira, S. C., Silva, C. C., Corrêa, A., Milech, V., Azambuja, S. A., Ramos, S. \& Bergmann, L. K. (2013). Ruptura de bexiga em um cão: relato de caso. Revista de Ciências Agroveterinárias, 12(Sup.):31-32.

Pulz, R. S., Kosachenco, B., Bagathini, S., Silveira, R. S., Menegotto, G. N. \& Cristina Schneider, B. C. (2011). A eutanásia no exercício da medicina veterinária: aspectos psicológicos. Revista Veterinária em Foco, 9(1):88-94.

Quinton, J.-F. (2005). Novos Animais de Estimação-Pequenos Mamíferos. São Paulo: Editora Roca. 
Reichmann, M. d. L. A. B. (2000). Controle de populaçôes de animais de estimação. In M. Técnico (Ed.). São Paulo: Instituto Pasteur.

Rivera, E. A. B., Amaral, M. H. \& Nascimento, V. P. (2006). Ética e bioética aplicadas à medicina veterinária. Goiânia, Goiás, Brasil: Editora da Universidade Federal de Goiás.

Santana, J. C. B., Rigueira, A. C. M. \& Dutra, B. S. (2010). Distanásia: reflexões sobre até quando prolongar a vida em uma Unidade de Terapia Intensiva na percepção dos enfermeiros. Revista Bioethikos, 4(4):402-411.

Santana, L. R. (2006). Compromisso de ajustamento de conduta celebrado entre o Ministério Público do Estado da Bahia e a Prefeitura Municipal de Salvador, relativo aos maus tratos praticados pelo Centro de Controle de Zoonoses de Salvador (BA). Revista Brasileira de Direito Animal, 1(1):313320.

Santoro, M. B. \& Arias, M. V. B. (2018). Complicações observadas em cães e gatos com doenças neurológicas. Pesquisa Veterinária Brasileira, 38(6):1159-1171.

Santos, L. A. C. \& Montanha, F. P. (2011). Eutanásia: Morte Humanitária. Revista Científica Eletrônica de Medicina Veterinária, 11-17.

Santos, T. C. C., Vulcano, L. C., Mamprin, M. J. \& Machado, V. M. V. (2012). Principais afecções da coluna vertebral de cães: estudo retrospectivo (1995-2005). Veterinária e Zootecnia, 13(2):144-152.

Silva, M. C., Fighera, R. A., Mazzanti, A., Brum, J. S., Pierezan, F. \& Barros, C. S. (2009). Neuropatologia da cinomose canina: 70 casos (2005-2008). Pesquisa Veterinária Brasileira, 29(8):643-652.

Sousa, V. R. F., Almeida, A. d. B. P. F., Barros, L. A., Sales, K. G., Justino, C. H. S., Dalcin, L. \& Bonfim, T. C. B. (2010). Avaliação clínica e molecular de cães com erliquiose. Ciência Rural, 40(6):1309-1313.

Teixeira, C. P., Barçante, L. \& Azevedo, C. S. (2018). Comportamento animal: Uma introdução aos métodos e à ecologia comportamental. Curitiba, Paraná, Brasil: Appris Editora.

Tilley, L. P., Smith, J. R. \& Francis, W. K. (2008). Consulta veterinária em 5 minutos: Espécies canina e felina. São Paulo: Editora Manole.

Tilley, P. L. \& Smith, F. K. W. (2015). Five-minute Veterinary consult: canine and feline: John Wiley $\&$ Sons.

Togni, M., Curtis, A., Vargas, D. P., Kommers, G. D., Irigoyen, L. F. \& Fighera, R. A. (2018). Causas de morte e razões para eutanásia em gatos na Região Central do Rio Grande do Sul (1964-2013). Pesquisa Veterinária Brasileira, 38(4):741-750.

Trapp, S. M., Iacuzio, A. I., Junior, F. A. B., Kemper, B., Silva, L. C., Okano, W., . . Sterza, F. A. M. (2010). Causas de óbito e razões para eutanásia em uma população hospitalar de cães e gatos. Brazilian Journal of Veterinary Research and Animal Science, 47(5):395-402.

Villas-Bôas, M. E. (2008). A ortotanásia eo direito penal brasileiro. Revista Bioética, 16(1):61-83.

World Society For the Protection Animal (1999)

Recebido: 20 de agosto, 2019.

Aprovado: 4 de novembro, 2019.

Publicado: 31 de novembro,2019.

Licenciamento: Este artigo é publicado na modalidade acesso aberto sob a licença Creative Commons Atribuição 4.0 (CC-BY 4.0), a qual permite uso irrestrito, distribuição, reprodução em qualquer meio, desde que o autor e a fonte sejam devidamente creditados. 